\title{
AT THE CONFLUENCE OF ORGANISATION DEVELOPMENT (OD) AND ORGANISATION IDENTITY THEORY (OIT): ENTER IDENTITY INTERVENTIONS
}

\author{
CL VAN TONDER \\ Department of Human Resources Management \\ Rand Afrikaans University
}

\begin{abstract}
The identity concept has been around in the form of "corporate identity" for some time, but its appearance as "organisation identity" is more recent. Emerging theory and initial empirical research suggest that an identity approach and "identity interventions" in particular, offer promising avenues to the organisation development practitioner for enhancing organisational focus, building resilience in the face of major change, and improving performance. Identity interventions in and of themselves, but also employed as pre-change interventions, build organisational capacity that would stave off premature organisational "death" and extend the organisation's life expectancy.
\end{abstract}

\section{OPSOMMING}

Die identiteitskonsep is in die vorm van korporatiewe identiteit reeds 'n geruime tyd in omgang, maar die verskyning daarvan as "organisasie-identiteit" is meer onlangs. Ontluikende teorie en aanvanklike empiriese navorsing suggereer dat 'n identiteitsbenadering en "identiteitsintervensies" in die besonder, belowende geleenthede aan die organisasie-ontwikkelingspraktisyn bied om organisasiefokus te verbeter, die organisasie se veerkragtigheid ten aanskoue van omvangryke verandering te bou, en prestasie te verbeter. Identiteitsintervensies op sigself bou organisasiekapasiteit, maar kan ook as voorveranderingsintervensies aangewend word wat premature organisasie "sterftes" sal vermy en die organisasie se lewensverwagting sal verleng.

It has become a truism that accelerated change and turbulence will be defining features of the future operating contexts of organisations ... change is and will be relentless, and organisations more than ever have to adapt or acknowledge the reality of a dramatically reduced life expectancy. While there is no factual grounding for views of the future, current reality confirms a rapidly reducing life expectancy for organisations during the mid 1990s around 40 to 50 years, and reducing (De Geus, 1997). Organisational death of course arrives in many forms such as bankruptcies, mergers, acquisitions, leveraged buy-outs, or simply seizing to exist as a legal entity. The all too common phenomenon of corporate restructuring (downsizing in particular) is not a form of death, but is considered a deferral of organisational death - effectively a means for buying time (D'Aveni, 1989). This very common change experience is consequently an early indication of the prospect of approaching organisational death. Needless to say, the financial costs of corporate failure i.e. organisational deaths and near-death experiences are staggering (cf. Hogan \& Overmyer-Day, 1994; Korten, 1995; Offerman \& Gowing, 1990), but it is the less often accounted for human and social costs that accompany the millions of lost employment opportunities, that are of primary concern.

Managerial attempts at averting organisational death or reversing a process of decline do not imbue confidence either. The failure rate, for example, in respect of a wide range of change initiatives including downsizing, restructuring, continuous improvement programmes, and the like is consistently reported as varying between $65 \%$ and $75 \%$ (cf. Beer \& Nohria, 2000; Grint, 1998; Mourier \& Smith, 2001). Institutional change management competence (if it exists) clearly pales into insignificance when considered from this context. There is really very little to suggest that formally mandated employees possess the capability to stem the reducing life expectation of organisations. Unsurprisingly, management still remains the major culprit (Jewell \& Linnard, 1992; Stuart, 1996), and evidence such as that cited here lends credence to the argument that managers, in their attempts to transform an

Requests for copies should be addressed to: CL Van Tonder, Department of Human Resource Management, RAU University, PO Box 524, Auckland Park, 2006 enterprise, could destroy the very capabilities that sustain the institution (Christensen \& Overdorf, 2000). While senior management certainly shoulders the lion's share of the responsibility, they are not alone in this predicament. Indeed, the mere presence of a Human Resource functionary in the organisation renders the latter an accomplice. The sting in this argument intensifies significantly if the organisation moreover employs behavioural scientists such as industrial psychologists and Organisation Development (OD) practitioners and indeed any functionary charged with the responsibility for change or change management.

In this context, organisational death (corporate failure) and even "near death" experiences represent the ultimate organisational change in the wrong direction and would be an indictment, in particular, of the OD practitioner's presence and contribution in the organisation. After all, the corporate expectation of the OD practitioner is that he/she will facilitate change for the better with both the organisation and the employee benefiting from intervention. It is unavoidable that the OD practitioner has to assume some responsibility and accountability for inappropriate organisational change. Moreover, with societal well-being dependent on the "health" of its organisations, organisational deaths or near-death experiences with their exceedingly high financial, human, and social costs amplify the Organisation Development practitioner's responsibility significantly. This responsibility generally entails the facilitation of change for the better i.e. in the interest of both the organisation and its employees, primarily through planned change interventions anchored in the behavioural sciences, and undertaken in collaboration with the client system. Given the ominous reality of a rapidly reducing organisational life expectancy, the key question is how and where does the $O D$ practitioner begin to provide the expected return on the corporate investment made in his/her appointment? Stated differently, where and how should change be facilitated "for the better" i.e. that the organisation's survival prospects are indeed strengthened?

To attempt to provide direction in response to this question we have to commence with the notion of corporate failure or organisational death. In this regard it has been argued and is 
now commonly accepted that the causes for corporate failure run deeper than surface level economic and managerial reasons, as these fail to adequately account for organisational death - the reasons are in fact substantially more psychological in nature (Levinson, 1994). Labich (1994, p. 22) has argued that when companies fail somebody effectively "... lost the mental model" of the business, and when this happens, "... decision-making becomes capricious and the company drifts" (p. 23). This phenomenon he described as an identity crisis and, according to Labich (1994) is the number one reason why many thousands of companies head down the path of corporate failure. This view is consistent with De Geus' (1997) subsequent research into longliving or enduring organisations that existed for 200 to 300 years or more, and which revealed $a$ strong sense of identity as one of four critical survival factors (the remaining factors being environmental sensitivity and alignment, tolerance of activities in the margin - not unlike decentralisation, and financial frugality). The significance of identity is further underscored with its emergence among the top strategic priorities of South African chief executive officers for the period 1999 to 2003 (Robertson, 1999).

Interestingly enough, the billions that companies annually invest in projecting a desired corporate identity (through corporate communications programmes) do not appear to impact on the rate of corporate "deaths" and consequently suggests firstly corporate identity may not be the phenomenon that Labich and De Geus refer to, and secondly, that more effective utilisation of at least some of the communications billions are possible. Some of the latter could more appropriately be channelled towards establishing what is suggested to be the pivot point of long term organisational survival or death, i.e. the organisation's identity proper. It is in this domain that the OD practitioner could add discernable value of a more sustainable and longer term nature. As will be argued, organisation identity theory (OIT) represents an alternative avenue as well as an intervention framework through which the field of OD could assist organisations in responding appropriately to rapid and revolutionary organisational change and in so doing enhance their adaptive and survival prospects. The purpose of this paper is consequently to introduce organisation identity as an emerging theory and platform for what could be termed an identity approach, and more specifically "identity interventions".

The discussion consequently leads with a brief consideration of the origins and nature of the identity concept and identity theory relevant to organisational settings. Preliminary empirical evidence and its implications for the field of OD set the stage for exploring and concluding with the notion of identity interventions.

\section{The theory in brief: Identity, corporate identity and organisation identity}

For the purpose of this discussion the relevant theory pertaining to the various concepts is only briefly introduced here. For a more comprehensive treatment of theory in the domain of identity and organisation identity as well as the current status and contemporary focus areas consult Van Tonder (1987; 1999) and Van Tonder and Lessing (2003) respectively. Balmer (2001), in turn, provides a comprehensive perspective on developments in the corporate identity field.

\section{Identity}

As practitioners and scholars we are comfortably familiar with the term identity, in part because of its popular use in the corporate marketing and public relations domains, but probably more so as a consequence of its wide acceptance and use by educators and educational psychologists. While many psychologists (personologists in particular) have recognised and articulated the identity concept under different labels, it is really Erikson $(1956,1959,1968)$ through his enduring work with identity development during childhood and adolescence that ensured that identity became a household term. Marcia (1966, 1967, 1976) further operationalised Erikson's identity concept in terms of different identity statuses and consequently also stimulated substantial, ongoing interest in the identity phenomenon. Ironically, our familiarity with the concept and its popularity in scholarly circles (in individual and childhood psychology, corporate communications and organisation theory) belies the inherent ambiguity of the concept and the difficulty of defining its nature.

The concept's first known occurrence in colloquial language however dates back to approximately $1570 \mathrm{AD}$ when it was used as an expression to convey the quality or condition of being the same, being absolutely or essentially similar and a sense of unity (Van Tonder, 1987). Erikson (1959) described it as the person's inner sense of sameness and continuity of character. Contemporary Oxford dictionaries of English indicate that the term identity originates from the Latin identitas and idem, meaning "the same", and describes it as the fact of being who or what a person or thing is. The very general and often cited view that identity is a response to the question "who am I?" (Schley \& Wagenfield, 1979 ) is validated by this more formal definition. The term is however more frequently used to refer to the person's uniqueness, solidarity, autonomy, continuity over time, and discreteness. Known as the "fact of identity", it is also referred to as objective identity and is differentiated from the person's "sense of identity" (or subjective identity). The latter, more specifically, refers to a person's sense of having or possessing an identity (Abend, 1974; Van Tonder, 1987).

\section{Corporate identity}

When we then turn to applications of the identity concept within organisational settings we observe two prominent literature streams. The first relates to the highly commercialised notion of corporate identity - mostly propagated by the corporate marketing and communications disciplines and is of a predominantly European origin. The second pertains to organisation identity which is primarily located in the organisation theory and management disciplines, and largely promoted by scholars in the USA.

Initially seven conceptual groupings within the corporate identity literature were identified (Balmer, 1995) but views of corporate identity have since clustered around three (Van Riel \& Balmer, 1997) or two literature streams or groupings (cf. Balmer \& Wilson, 1998; Van Tonder, 1999; Van Tonder \& Lessing, 2003). The earlier arguments for extracting more than two schools of thought from the existing literature base are not convincing and consequently the notion of two distinct perspectives on corporate identity is supported. They are differentiated on the basis of where they place the emphasis and as a consequence they are not regarded as being mutually exclusive. First and foremost in this regard are those that accentuate the visual and design elements of the organisation as being the essence of corporate identity. This is the more traditional, established and prominent view of corporate identity and from this perspective it is typically defined as the visual manifestation and projection of a desired identity - notably through means such as the company's name, logo, corporate colours, tagline, slogans, and symbols, but also the physical facilities of the organisation. A characteristic feature of this approach is the prominence of the visual elements or components of the organisation that provide the leverage through which the perceptions of various stakeholders can intentionally be influenced or manipulated in a preferred direction. In essence it is argued, perhaps oversimplistically, that when stakeholders identify and accept the organisation's visible identity, sales of its products and services (in fact its market position in general) are greatly improved which enhances medium term success prospects.

The second school of thought equates corporate identity to the organisation's innate or distinct personality or character and tends to emphasise the organisation's mission, philosophy, 
and culture as core components of the corporate identity. Those who support this view argue that the visual attributes of the organisation (the primary focus of the first school of thought) are merely manifestations of the underlying, distinctive character of the organisation. They consequently suggest alignment and congruence between organisation character and appearance. The essential difference between these two schools of thought centres on the emphasis and role placed on the visual attributes of the organisation, where the former considers this to be an end in itself, and the latter views it as primarily an instrument "in support of". For our purposes we will subscribe to the a view of corporate identity as those attributes of the organisation that are purposefully employed to project or portray the organisation to various stakeholders, predominantly through planned and persuasive visual means. Corporate image on the other hand, which is often confused with corporate identity, is essentially a perception of the company which may include the beliefs, experiences, feelings, knowledge, attitudes or perceptions that stakeholders hold in respect of the organisation and which is typically the result of, among other, efforts to project a desired corporate identity.

A groundswell within the corporate identity domain is however beginning to develop around calls for a greater emphasis and focus to be placed on the organisation's innate or distinct personality or character and prominent authors and practitioners now argue that too much emphasis has been placed on the world outside the company and not enough on the world inside it (Olins, 1996, p. 18). This view is aptly illustrated by the suggested metaphor of a "reversible raincoat" (Glover, 1993), which conveys the absolute alignment and seamless integration of "internal" and "external" yet also proposing that the "internal" enjoys precedence i.e. "becoming the outside".

\section{Organisation identity}

Organisation identity, which constitutes the second application of the identity concept within organisational settings can in effect be equated to Glover's "inside". Four salient or primary streams of thinking i.e. the psychoanalytic, social identity, communication, and classical approaches to the subject have been discerned in the sparse organisational identity literature base (Van Tonder, 1999).

Theoretical diversity similarly characterises the second application of the identity concept within organisational settings - to the extent that four salient or primary streams of thinking have been discerned in the sparse organisational identity literature base (Van Tonder, 1999). These are in brief the psychoanalytic approach (for example Czander, 1993; Diamond, 1993; and more recently Brown \& Starkey, 2000) that applies psychoanalytic concepts and theories to the organisation and views identity inter alia as an unconscious defence against anxiety; the social identity approach (see for example Ashforth \& Mael, 1999; Hogg \& Terry, 2000) that argues that the individual and by implication also the organisation as unit of analysis seeks a positive social identity and does so by attempting to affiliate with a group or groups (or industries or associations if at the organisational level) that are sufficiently attractive to seek belonging to it; the communication approach (Hecht, 1993) which tends to view organisation identity as the process of communication and self-expression in which the organisation engages, and through which it exchanges messages about itself; and the classical approach for it more closely approximates the psychological parameters of Erikson's (1959, 1968) original concept of identity and essentially equates organisation identity to the distinctive, core and enduring features of the organisation.

Despite the obvious variation in the meaning that the different schools of thinking ascribe to identity in an organisational setting, there appears to be a general acknowledgement of its importance in organisational functioning and scholars concur that it has a significant and pervasive impact on the organisation's functioning, although the dynamics of this is not always clear.

Our interest is however directed at the classical approach (represented by Albert \& Whetten, 1985; Dutton \& Dukerich, 1991; Van Tonder, 1987, 1999), firstly as it more closely approximates (and is grounded in) the psychological parameters of Erikson's $(1959,1968)$ original concept of identity, and secondly, is more pertinently concerned with the identity of the organisation-as-organisation (as unit of analysis). Scholars residing within this category typically take Albert and Whetten's (1985) definition of organisation identity as point of departure and it is usually defined as those features of the organisation that are considered core, distinctive and enduring. This definition serves as a useful translation and operationalisation of the organisation's identity (distinctive character) or stated differently, its response to the question "who am I as organisation?"

Current organisational practice acknowledges and invests heavily in the notion of corporate identity and more recently the related concept of corporate branding which, overwhelmingly, reflects a contrived notion of the organisation's desired or ideal character. Awareness of the factual organisation identity (the organisation's character in residence so to speak) is however nonexistent and in practice there is consequently no talk of a relationship between corporate and organisation identity. The literature however indicates otherwise and some convergence is for example observed between the views propagated in some quarters in the corporate identity field (cf. Balmer, 1995; Glover, 1993; Olins, 1996; Van Rekom, 1997; Van Riel \& Balmer, 1997) and proponents of the classical approach to organisation identity. In keeping with the view of for example Kiriakidou and Millward (2000) and Van Tonder (1999), corporate identity is viewed here as the "external" manifestation of organisation identity (which is core) and, for obvious reasons, should be congruent. Our focus for the remainder of this discussion is consequently directed at organisation identity, which proceeds with a brief summary of the essential theory in respect of organisation identity.

\section{Essentials of organisation identity theory (OIT)}

If we extract the core theoretical propositions from the analysis of the different theoretical perspectives and contributions, and the proposed theoretical framework offered by Van Tonder (1999) it would appear that organisation identity (OI):

- Refers to who and what the organisation is i.e. its distinctive character. The latter is most often operationalised as those organisational features that convey the organisation's distinctiveness, and are core and enduring. It is a dynamic, organisation-level self-description, and an "answer" offered in response to the question: Who am I as organisation?

- OI is not self-evident, as it is constructed at a preconscious level in the form of a collective cognitive schema or meaning structure (it is a hidden or "below-the-surface" phenomenon and as a result organisational members are generally unaware of its presence and nature).

- OI is collectively held by employees and constituencies (e.g. management, labour, clients, partners, and other stakeholders) as tacit understandings of who and what the organisation is.

- OI is established mostly in social settings/collective endeavours such as management meetings, social gatherings, workshops or retreats, planning sessions, and the like, and is constructed from character-relevant knowledge obtained from the environment and the organisation itself, and is revisited and updated on a continuous basis. This knowledge is analysed, compared with other position markers (role models or benchmarks e.g. industry leaders), and conclusions are integrated in the organisation's self-description. To the extent that this self-description reveals attributes and features that 
endure over time, are core to the organisation, convey its distinctiveness, and further facilitates a sense of solidarity, to this extent it will possess a distinctive character. This is known as the fact of identity and is simply referred to as the organisation's identity.

- OI enters, or rather, is "forced" into the organisation's awareness (becomes more conscious and visible to employees and constituencies) as a sense of identity i.e. a subjective awareness and experience of who and what the organisation is. It is mostly a sense of deficient, inadequate, or inappropriate identity that surfaces, and it occurs during periods of transition or change (upheaval), when the organisation is on the verge of gaining a clear identity or about to enter a crisis stage. When the sense of identity diffusion or loss is intense and extreme, it is referred to as an identity crisis, which will initiate identity search behaviour that could take many different forms and costly turns. Identity will remain at a conscious level until such time that the identity problem (or identity crisis) has been resolved (a clear identity is established or regained) upon which the identity issue is once again consigned to a preconscious level where it exerts a tacit yet powerful influence.

- OI of course has as its sole purpose to define and "separate" (differentiate) the organisation from its environment, which will reveal the direction and scope of needed adaptation and in turn will facilitate appropriate organisational focus, and concentration and channelling of effort and other resources. Organisation identity consequently has a pronounced and pervasive impact, as it functions as a framework that filters and directs the organisation and its employees' perception, interpretation, decision making and action from "below-the surface". From this perspective we would expect identitystrong organisations to be more focused, deal with change more effectively, perform better, and to outlive identity-weak organisations.

\section{Preliminary evidence}

Very few empirical studies have to date been conducted, with case studies appearing to be the preferred methodology (Albert \& Whetten, 1985; Dutton \& Dukerich, 1991). Most of the preliminary evidence is however obtained from an exploratory study into organisation identity (Van Tonder, 1999, 2000) that engaged 153 top executives (CEO/executive director level). The 10 listed companies were firstly drawn from top and worst performing companies over a four-year period and secondly from several industry sectors (mining, retailing, medical care, financial services/banking, manufacturing and fisheries). An ex post facto field study with triangulation as primary methodology (involving both quantitative and qualitative data gathering strategies) was undertaken. While a detailed review of the study is beyond the scope of the current discussion it is of interest to note that the study's findings, in general, appeared to echo the views expressed by De Geus (1997) and Labich (1994), and to provide support for most of the theoretical propositions cited earlier.

Although organisational size, which is a manifestation of the organisation's life cycle-bound stage of development, appeared to mediate the identity-performance relationship in some instances (sheer size could sustain acceptable performance levels/returns for a limited period of time despite the prevalence of identity problems), this was not true for top performing companies with strong identities. Notwithstanding this, the study clearly revealed that organisations with a clear and strong sense of identity, when compared to their counterparts who experienced diffused identities or identity crises:

- Presented with greater clarity of purpose and focus, exuded an inner confidence, were likely to be in or entering a growth stage in their life cycle, and performed substantially better on a variety of performance indices. When sense of identity was uncertain (diffused) organisational focus and performance were also adrift, which validates Labich's (1994) comments (cited earlier).
- Displayed strong identities regardless of scope of operations and size of asset base, whereas identity diffusion was more prominent in larger organisations suggesting that if identity is not consciously attended to (managed), identity problems are likely to emerge during the maturation/elaboration of structure stage in the organisational life cycle - on the verge of entering a decline stage.

- Attended more to organisational attributes that could be described as internal and more directly relevant to organisational performance e.g. long term objectives, success orientation, culture, stakeholders/clients, systems, employees, and work climate, whereas those whose identities were diffused or unclear, displayed a preoccupation with peripheral features such as corporate identity and image, social role/prominence, its name, and size of the asset base.

- Were more tolerant of changes in non-core attributes (allowed greater relaxation of controls in these areas) while organisations with deficient identities tended to be more prescriptive and attempted to tighten (control) practices and organisational actions to a greater extent.

- Appeared to ride (tolerate and survive) the waves of turbulent and revolutionary change (in this instance radical sociopolitical change and severe macro-economic challenges) far better than those with diffused, fragmented and / or inadequate identities who reported "survival struggles" and "crunch times".

\section{Implications of an identity approach for the field of OD}

The argument for adopting an identity-prominent approach stems from the unsurprising finding that top performing ("successful") organisations in the cited study revealed a positive and clear sense of identity as compared to poor performing organisations that conveyed a sense of identity diffusion or identity crisis. The weight of evidence suggests that an identity approach offers an alternative vantage point for approaching among other, organisational performance issues.

Several implications immediately become apparent when the organisation is viewed through an identity lens. Central to these is of course the notion that organisation identity is an invisible phenomenon that is difficult to access. In this regard it resembles organisation culture - the difference being that organisational culture speaks to the "way we do things around here" while organisation identity addresses the "who am I" issue. Who and what I am (identity) clearly precedes and influences what I do and how I do it (culture) and where I intend going (e.g. strategy). From this perspective organisation identity is at the root or core of the organisation where it operates as an invisible decision framework (or "selfpolicy") that exerts a pervasive influence on all aspects of organisational functioning such as management, culture, strategy, and the like. It follows logically that where this collectively held schema is incoherent and insufficiently integrated (presenting in an inadequate or deficient identity) that members of the organisation may interpret this differently and that the potential for different actions as well as disagreement or conflict could increase significantly. A coherent and clear organisation identity is consequently desirable. In practice the significance and potential usefulness of the question "who am I/we as organisation?" in guiding the organisation in its day-to-day functioning and along its growth and development trajectory, is seldom contemplated.

It will be argued that the issue of organisation identity has always been present in most if not all interventions with which OD practitioners have busied themselves in the past, but that they may have been largely unaware of the fact that they were simultaneously working at the identity level, simply as a result of the focus engendered by the nature and level of the client's "presenting" dilemma or need. To illustrate: when we engage in strategic planning sessions with a client organisation, we essentially address what the organisation wants to achieve in the 
long term and invest substantial time in planning how the organisation will go about securing identified long term objectives (strategy per se) by taking account of the prevailing circumstances and, most importantly, the organisation's capabilities and vulnerabilities. The latter, in part, addresses who the organisation is and so the question "who am I as organisation?" has always been present but, in a manner of speaking, lurking out of sight. It is argued here that this question should be recognised, consciously and adequately addressed, and "agreement" secured among the majority of the stakeholder constituencies on who and what the organisation is. An explicit, clear and fairly detailed response to the question "who am I as organisation?" (i.e. a holistic self-description conveying its distinctive character) will yield an enabling framework that will facilitate "agreement" on many functioning parameters of the organisation with substantially less effort required than traditional means may demand.

Major, often difficult, change initiatives invariably involve some form of culture change, which is typically approached through planned (and resisted) change initiatives. An identity perspective would instead imply that change could be more effectively leveraged through surfacing and working with the organisation's identity e.g. by securing "agreement" on an appropriate and specified identity for the organisation which will influence/impact the organisation in toto. Moreover, it has to be acknowledged that the state of the organisation's identity will in any event direct its focus, for example, when identity is weak and fragmented, a preoccupation with "peripheral" issues such as corporate identity, social role and profile, and the like can be expected. This is not only distracting to current focus, but exceedingly costly in the short term and likely to compromise the organisation's long term survival prospects. Working with identity consequently allows the OD practitioner and change agent to engage change closer to the organisational core in a less demanding and costly manner, but where it will nonetheless tacitly influence all organisational choices and decisions (actions). To a substantial degree organisation identity then relieves the OD practitioner, behavioural scientist and manager of the rather wasteful focus on multiple surface level leverage points for change that are generally demanding in terms of time and effort (e.g. culture change), and whose likely outcomes are often uncertain and in any event directed by below-thesurface phenomena, such as identity. When we work with identity we effectively jump the queue of many potentially promising change levers to work with the very small "inner circle" of significant change levers.

The establishment and maintenance of a clear, coherent and strong organisation identity (as indicated by the organisation's sense of identity) should be a central if not overriding pursuit of the OD and HR practitioner, clearly, as this enhances focus, contributes to improved performance, reduces the organisation's vulnerability to radical change (serves as a buffering mechanism) and strengthens its long term survival capabilities and prospects. Indeed, if established, it acts as a powerful perceptual filter (hence the increase in focus) but also as a "below-the-surface" force (and framework) that directs/guides behaviour and decision making (consider for example how the response to who and what the organisation is, will influence the selection and development of an appropriate strategic vision, or the choice of operational strategies). Managerial routines and practices will consequently benefit substantially when reconsidered from an organisation identity perspective, and managerial focus, energy, and related resources are directed, at least to some extent, towards the establishment, maintenance, and/or "management" of identity.

Once a clear, coherent, and strong identity has been established, it should be leveraged by aligning current and future philosophies, policies and practices with who and what the organisation is (what we can refer to as identity-alignment interventions). Not only would this contribute to an overall improvement in organisational functioning but simultaneously build coherence and consistency in outlook and practice (valued by customers and clients), and a sense of unity/"we" - effectively reinforcing the distinctive character of the organisation.

Efforts to surface, clarify, and (re)confirm the organisation's identity should serve as a precursor to any change initiative in particular before entering into, and upon conclusion of major change, as this will facilitate movement through, and improved coping during the change process. Post-change consolidation i.e. settling down and re-establishing focus, will similarly be markedly accelerated. Empirical evidence suggests that the success prospects and sustainability of identity-aligned change programmes (particularly those that involve second order change) are substantial, while change initiatives that are not aligned with the organisation's identity are likely to be rejected (cf. Fox-Wolfgramm, Boal \& Hunt, 1998).

Ideally organisation identity or distinctive character (operationalised as the distinctive, core and enduring features of the organisation) should be measured and monitored, but it may initially be necessary to engage in concerted efforts towards the establishment and articulation (followed by maintenance) of a clear and distinctive identity. An important consideration though, is that objective identity (being tacit in nature) is accessed through its more conscious manifestation namely the sense of identity. The latter is therefore the first "port of call" when engaging in what we refer to as identity interventions.

\section{Identity interventions}

Identity interventions represent the confluence and indeed meshing of organisation identity theory and the science and practice of Organisation Development (OD). Organisation Development technology for the greatest part comprises the arsenal of interventions that translate behavioural science into structured change facilitation activities. "Identity interventions" gracefully fit within this category and refer to that class or group of interventions that intentionally target the organisation's identity as a central consideration to the organisation's health and survival. As a class of interventions they would aim to strengthen the organisation's sense of who and what it is - more specifically, they would assist the organisation in identifying, articulating, establishing, supplementing, or maintaining its distinctive character, or leveraging it to the benefit of the organisation and its membership. The need for interventions of this nature would be indicated in particular when the organisation conveys an inappropriate (incongruent), uncertain or diffused identity, or appears to experience a loss of identity (in its most severe form referred to as an identity crisis). The prevailing identity status of the organisation will determine the scope and intensity with which the organisation will have to engage in identity analysis and development processes. In the event of an identity crisis the intervention will be more comprehensive and intense than when identity is validated as a pre-emptive measure before the organisation engages major change. An outline of alternate identity interventions differentiated on the basis of scope and intensity of intervention is indicated in Table 1.

Identity interventions are best implemented through large scale methodologies such as identity search (or validation) conferences - not unlike the well-known future search conferences or "getting the whole system in the room" interventions as these would offer the collective setting necessary to effect change to collectively held schemata. The primary and challenging task of the OD practitioner during identity interventions and in particular identity establishment and identity change, is to surface, facilitate and "agree" a common and explicit statement on who and what the organisation (or department or team) is. This implies surfacing relevant views and perspectives of the organisation, 
TABLE 1

\section{TYPOLOGY OF IDENTITY INTERVENTIONS}

Intervention categories

designated on the basis

of the scope and intensity

of intervention

\section{Purpose and utilisation}

Identity interventions generally aim to establish, maintain, or benefit from a clear and stable organisation identity as conveyed by those features or attributes of the organisation that are unique, core, and enduring and which are presented in response to the question who am I/we as organisation?

1.1 Identity validation

Purpose: To raise organisational members' awareness in respect of the organisation's identity and to make the organisation's identity more salient - as a pre-emptive or anticipatory intervention.

Utilised when the organisation has a firm, stable and clear identity but is on the verge of engaging profound and major change or is entering or commencing a transition from one life cycle stage to another. It is employed as a pre-emptive (pre-change) and context setting intervention and essentially involves a surfacing and confirmation of the organisation's (existing and appropriate) identity in order to ensure that those aspects of the organisation identity that are valued, are retained and remain intact during and emerging from the change. In this role identity serves the function of buffering the organisation against adverse change affects.

1.2 Identity maintenance

Purpose: To maintain an appropriate (clear and stable) organisation identity amidst a continuously changing operating context and to ensure an appropriate degree of organisation-environment alignment in response to adaptation challenges posed by a changing operating environment.

It involves regular identity "checks" (identity validation interventions) that have to ensure that the organisation's identity does not "drift" - in particular when the organisation is engaged in prolonged, demanding operating circumstances. Excessive organisational drift, which eventually would lead to radical and revolutionary change, is countered by the focus that stem from regularly revisiting the organisation's identity. In this role identity serves as "position marker" or evaluation frame.

2. Identity alignment

Purpose: To ensure that the organisation acts in an identity-consistent manner and that identity parameters are not inadvertently compromised through organisational decisions or actions (initiatives) in which the organisation may become absorbed and which possesses the potential to impact identity (e.g. the annual strategy crafting sessions, or the appointment of an executive from outside the organisation).

The organisation's known (previously established or confirmed) identity is used as a platform and framework in terms of which major decisions, initiatives or strategies are considered and the nature and implementation of these decisions or initiatives are consciously scoped, planned and articulated in an identity-compatible manner. In this application identity is employed in a role similar to the "packaging" and "quality control" stages in a production facility.

3.1 Identity elaboration or establishment

Or

3.2 Identity change

(if wholly inappropriate)
Purpose: To facilitate the establishment of a clear and stable organisation identity.

This intervention (or series of interventions) is typically employed when the organisation experiences an identity crisis (a sense of lost identity), identity diffusion, or finds itself in an identity search stage (e.g. when the scope, diversity and complexity of the organisation's operations are such that the organisation is incapable of providing a holistic self-description that conveys its distinctive i.e. a clear and consistent response to the question "who am I").

It is the most demanding and intensive of interventions and requires extensive data gathering and analysis of the organisation in order to extract the core, enduring and distinctive features that together constitute its distinctive character. It requires a series of systematic, system-wide and collective activities/interventions during which the concept of who and what the organisation is, is intensely debated and reviewed from comparative data (e.g. industry and competitor analyses, stakeholder surveys, market research, benchmarking exercises) as well as existing "internal" organisational data generated over an extended period of time (e.g. historical / archival data on founding, development, performance, succession in leadership, internal surveys, etc.). It effectively implies surfacing and dislodging ("unfreezing") the existing (tacit) and fragmented concept of who and what the organisation is, and through valid and reliable data extracting, consolidating and entrenching ("refreezing") the organisation's identity. Identity in this context can be equated, metaphorically, to a "compass" (cf. Labich, 1994) that has been absent and is needed to set a ship that is adrift in the open seas, on its course.

Identity change is indicated when a long held organisation identity is partially or wholly invalidated for example by acquisition or mergers, and now requires meaningful alteration in a more valid direction. Using the same metaphor, the "compass" in this intervention effectively requires recalibration. but also to supplement these with identity-relevant data secured from internal and external sources, and to facilitate the integration of these in a manner that is true to the organisation, and accepted and sanctioned by its members. Value is derived not only from identity interventions that constitute the reactive "correction" of survival-threatening identity crises, but in particular as pre-emptive interventions i.e. interventions that precede and pre-empt and effectively prepare the organisation for major endeavours, change processes or other interventions. They are effectively preinterventions.

\section{Diagnosis}

For diagnostic purposes several entry points (or avenues) can be discerned through which the organisation's identity can be approached and include

- the organisation's sense of identity (whether clear or diffused /uncertain),

- organisational focus (whether clear and targeted or unclear/inappropriate or adrift) and
- organisational stage of development (for example entering, or emerging from growth, consolidation or decline stages indeed, any major change event).

It was indicated earlier that the meaning structure concerned with the distinctive self-description of the organisation (objective identity) exists at a preconscious level which complicates its access and assessment. In this regard it was argued that the most appropriate route to this meaning structure would be through the sense of identity (subjective identity). Both theory and practice have indicated that the sense of identity will drift into consciousness when it is experienced as inadequate. It was for example observed that organisations that experienced identity difficulties were quite conscious of this fact and voiced it in identity terminology (Van Tonder, 1999). When organisational members (for example executives) consequently introduce identity terminology in discussions, meetings, or surveys, this is diagnostic of a deeper uncertainty about the distinctive character of the organisation. The sense of identity however is 
unlikely to emerge from the preconscious in this manner when the organisation is confident and secure in its identity. Interventions concerned with the validation and maintenance of the organisation's identity (refer Table 1, interventions 1.1 and 1.2 ) are therefore pre-emptive in nature and aim to avoid the onset or development of future identity dilemmas, while intervention 2, which is more concerned with congruence between the organisation's identity and its actions, presupposes either identity validation or maintenance.

Obviously when the organisation conveys a sense of inadequate identity, identity establishment or identity change interventions are indicated (refer Table 1, interventions 3.1 and 3.2). Some caution however has to be exercised before engaging in these resource-intensive interventions as not all subjectively experienced identity deficiencies necessarily signify a fragmented objective identity (a lack of integration at cognitive schema level). The possibility exists (albeit a small probability) that employees may simply be inadequately aware or not suitably "informed" of the "fact" of the organisation's distinctive character. In such instances an identity validation approach (intervention 1.1) is a more appropriate point of commencement prior to launching into an identity establishment intervention (intervention 3.1).

Organisational focus is a particularly useful diagnostic source and where focus may be trailing off or appears uncertain, it is likely to be suggestive of an inadequate underlying identity or inadequate awareness of the organisation's underlying organisation identity. Either way, focus will bear out an expressed sense of inadequate or inappropriate identity. The onset of major change and organisational transitions between stages in its life cycle are of more indirect 'diagnostic' value in that it does not indicate the presence of an identity deficiency but reminds the manager and OD practitioner of the identitychange relationship and effectively alerts them to the possibility that identity will come under pressure. In this instance, again, proactive identity validation or maintenance approaches (interventions 1.1 and 1.2) are indicated. When managers use identity terminology to convey a sense of inadequate identity and this coincides with or occurs immediately prior to some approaching change event, it provides early signs of the potential character-altering nature of the change (which is likely to be major and radical).

Moreover, any major change will prompt uncertainty (and initiate "unfreezing" in the Lewinian sense). If the organisation's identity is clear and stable prior to entering major or radical change, the impact on the organisation is likely to be reduced and it is bound to emerge from the transition in a substantially better position than those organisations whose identities were less certain. The converse also holds true: if the organisation's identity is diffused or it experiences a "loss of identity", we can expect that the transition will be character altering and traumatic. We also know from life cycle theories that start-up conditions and the onset of decline (when the organisation moves out of the consolidation/maturation and elaboration stages) are periods during which the organisation is particularly vulnerable to change. By implication OD practitioners should pre-empt these stages and engage in identity-strengthening interventions (i.e. identity validation or maintenance) in an attempt to minimise the potentially disruptive influence of change during these transitions.

\section{Implementation}

Identity interventions will require convincing data-driven perspectives and arguments to negate currently held but inappropriate beliefs about the organisation's character, as well as equally powerful and convincing arguments in support of altered identity definitions. The data to be used in support of these interventions, is normally sampled through the organisation's interaction with its environment and the feedback so obtained is absorbed, subjected to substantial analysis and then used to compare and categorise the organisation in terms of "position markers"/benchmarks or role models. It follows that these channels be pursued to obtain data for input into a structured process of analysing and reflecting on who and what the organisation is. Surveyguided research (e.g. stakeholder and client surveys) becomes very useful means of securing identity-relevant information as a supplement to (possibly "stale") information currently embedded in the identity schema of the organisation. Action research and Appreciative enquiry are likewise proven methodologies that should produce valid identityinformation with the added benefit that their process nature and structure will positively influence the process of assimilating the data.

Interviews, questionnaires and several other data gathering methods such as the Repertory Grid, Semantic Differential scales, and the 20 Statements Test have been used successfully when questions seeking identity data were constantly framed within the context of position markers in the organisation's operating context. To evoke comparative thinking a question such as the following should suffice: "In what respects is your company unique when compared to its peer organisations in the industry sector?" Peer organisations can of course be substituted with competitors, role models, benchmarks, or the names of specific, known companies. Information obtained from different stakeholder constituencies within and outside the organisation (when pooled as a single data set) will provide a rich and demanding analysis task ideally suited to a dynamic and interactive setting (e.g. small group work during a 3-day "identity breakaway"). This analysis process in itself is a critical stage and a major intervention that should best be undertaken within formats similar to that of, for example "Getting the Whole System in the Room" or modified "Search Conferences" or "Future Search Conferences" (cf. French \& Bell, 1999). During these large-scale interventions organisational members and stakeholders collectively sift through, extract, and reason around the emerging commonalities - under the guidance and supervision of experienced OD facilitators.

While OD technology has served the field of OD well during the past five to six decades, the context within which OD is researched and practiced has changed significantly. The nature and form of change with which organisations now have to contend, are assuming a character that necessitates more regular adaptive responses of significant scale. Understandably the life expectancy of organisations within this global, hypercompetitive, and technology- and information-rich context will be declining when organisations and the initiatives they engage in are not focused on that which clearly articulates the adaptation gap and "survival challenge". It is in this context that identity interventions, which represent the practice component of an approach premised on organisation identity theory, offer a significant contribution.

\section{Concluding perspectives}

It is intuitively logical that who and what we are will direct our focus and that focus instructs energy expenditure, which in turn produces outcomes. Yet, this logic is seldom acknowledged or embraced ... simply because the "who am I?" question as starting point of the logic is taken for granted and seldom considered. Ironically, it is a clear and coherent response to this seemingly uncomplicated but difficult-toanswer question that tends to remove a great deal of complexity from the management of organisational life. The observation that organisations with strong, coherent and clear identities tended to deal substantially better with transformational and radical change when compared to identity deficient organisations, calls to mind a comment by Erikson (1964, pp. 95-96) several decades ago: "Identity connotes the resiliency of maintaining essential patterns in the process of 
change. Thus, strange as it may seem, it takes a well-established identity to tolerate radical change, for the well-established identity has arranged itself around basic values which cultures have in common. The focus and resilience born from a clear organisation identity may well show up organisational change as being somewhat more digestible. Organisation identity seems to hold one of the very few keys to longer term organisational survival.

\section{REFERENCES}

Abend, S.A. (1974). Problems of identity: Theoretical and clinical applications. Psychoanalytic Quarterly, 43, 606-637.

Albert, S., \& Whetten, D.A. (1985). Organisational identity. In L.L. Cummings \& B.M. Staw (Eds.), Research in organisational behavior, Vol. 7. Greenwich, CT.: JAI Press

Ashforth, B.E., \& Mael, F. (1989). Social identity theory and the organisation. Academy of Management Review, 14, 20-39.

Balmer, J.M.T. (2001). Corporate identity, corporate branding and corporate marketing: Seeing through the fog. European Journal of Marketing, 35 (3/4), 248-291.

Balmer, J.M.T. (1995). Corporate branding and connoisseurship. Journal of General Management, 21 (1), 24-46.

Balmer, J.M.T., \& Wilson, A. (1998). Corporate identity: There is more to it than meets the eye. International Studies of Management \& Organisation, 28 (3), 12-31.

Beer, M., \& Nohria, N. (2000). Cracking the code of change. Harvard Business Review, May-June, 133-141.

Brown, A.D., \& Starkey, K. (2000). Organizational identity and learning: A psychodynamic perspective. Academy of Management Review, 25 (1), 102-138.

Christensen, C.M., \& Overdorf, M.(2000). Meeting the challenge of disruptive change. Harvard Business Review, March-April, 67-76.

Czander, W.M. (1993). The psychodynamics of work and organizations: Theory and application. New York: Guilford Press.

D 'Aveni, R.A. (1989). The aftermath of organizational decline: A longitudinal study of the strategic and managerial characteristics of declining firms. Academy of Management Journal, 32 (3), 577-605.

De Geus, A. (1997). The living company: Growth, learning and longevity in business. London: Nicholas Brearley Publishing.

Diamond, M.A. (1993). The unconscious life of organizations: Interpreting organizational identity. Westport, Connecticut: Quorum Books.

Dutton, J.E., \& Dukerich, J.M. (1991). Keeping an eye on the mirror: Image and identity in organisational adaptation. Academy of Management Journal, 34, 517-554.

Erikson, E.H. (1956). The problem of ego identity. Journal of the American Psychoanalytic Association, 4, 56-121.

Erikson, E.H. (1959). Identity and the life cycle. Psychological Issues, 1

Erikson, E.H. (1964). Insight and responsibility. New York: Norton.

Erikson, E.H. (1968). Identity, youth, and crisis. New York: Norton.

Fox-Wolfgramm, S., Boal, K., \& Hunt, J. (1998). Organizational adaptation to institutional change: A comparative study of first-order change in prospector and defender banks. Administrative Science Quarterly, 43, 87-126.

French, W.L., \& Bell, Jr. C.H. (1999). Organization development: Behavioral science interventions for organization improvement (6 $6^{\text {th }}$ Edition). Upper Saddle River, NJ: PrenticeHall.

Glover, R.K. (1993). Identity building begins on the inside: External views reflection of a company's internal practices, habits. Business Marketing, August, 38.
Grint, K. (1998). Determining the indeterminacies of change leadership. Management Decision, 36, 503-508.

Hecht, M.L. (1993). 2002 - A research odyssey: Toward the development of a communication theory of identity. Communication Monographs, 60 (1), 76-82.

Hogan, E.A., \& Overmyer-Day, L. (1994). The psychology of mergers and acquisitions. In C.L. Cooper \& I.T. Robertson (Eds.), International review of industrial and organizational psychology, Volume 9. Chichester: John Wiley.

Hogg, M.A., \& Terry, D.J. (2000). Social identity and selfcategorization processes in organizational contexts. Academy of Management Review, 25 (1), 121-149.

Ind, N. (1992). The corporate image. London: Kogan Page.

Jewell, R.E., \& Linard, K.T. (1992). Evaluating corporate plans and the corporate planning process. Evaluation - making it work: Proceedings of the International Conference of the Australian Evaluation Society, 2, Paper 59, Melbourne.

Kiriakidou, O., \& Millward, L.J. (2000). Corporate identity: External reality or internal fit. Corporate Communications: An International Journal, 5 (1), 49-58.

Korten, D.C. (1995). When corporations rule the world. San Francisco: Berrett-Koehler Publishers.

Labich, K. (1994). Why companies fail. Fortune, 130 (10), 22-32.

Levinson, H. (1994). Why the behemoths fell: Psychological roots of corporate failure. American Psychologist, 49, 428-436.

Marcia, J.E. (1966). Development and validation of ego-identity status. Journal of Personality and Social Psychology, 3, 551-558

Marcia, J.E. (1967). Ego-identity status: Relationship to change in self-esteem, "general maladjustment" and authoritarianism. Journal of Personality, 35, 118-133.

Marcia, J.E. (1976). Identity six years after: A follow-up study. Journal of Youth and Adolescence, 5 (2), 145-160.

Mourier, P., \& Smith, M. (2001). Conquering organizational change: How to succeed where most companies fail. Atlanta: CEP Press.

Offerman, L.R., \& Gowing, M.K. (1990). Organizations of the future: Changes and challenges. American Psychologist, 45, 95-108.

Olins, W. (1996). The energy of identity. Marketing Focus, April, 18-20.

Robertson, D. (1999). Business leaders keenly focused on action. Sunday Times, Business Times, April 11, 1-1.

Schley, W.R., \& Wagenfield, M.O. (1979). Identity degradation and mental disorder: An empirical assessment of the conduct impairment scale. American Journal of Community Psychology, 7 (1), 19-30.

Stuart, R. (1996). The trauma of organisational change. Journal of European Industrial Training, 20 (2), 11-15.

Van Rekom, J. (1997). Deriving an operational measure of corporate identity. European Journal of Marketing, 31 (5/6), 110-122.

Van Riel, C.B.M., \& Balmer, J.M.T. (1997) Corporate identity: The concept, its measurement, and management. European Journal of Marketing, 31 (5/6), 340-355.

Van Tonder, C.L. (1987). Kleingroepidentiteit. Unpublished master's thesis, Rand Afrikaans University, Johannesburg.

Van Tonder, C.L. (1999). Organisation identity: An exploratory study. Unpublished doctoral thesis, Rand Afrikaans University, Johannesburg.

Van Tonder, C.L. (2000). Organisation identity: Exploring a "new" avenue for intervention and performance improvement. In K. P. Kuchinke (Ed.). Proceedings of the 2000 AHRD Conference, Raleigh-Durham, NC, USA, vol. 1, 268-276.

Van Tonder, C.L., \& Lessing, B.C. (2003). From identity to organisational identity: Evolution of a concept. SA Journal of Industrial Psychology, 29 (2), 20-28. 